\title{
Prohydrojasmon Promotes the Accumulation of Phenolic Compounds in Red Leaf Lettuce
}

\author{
Shinya Takahashi ${ }^{1,2,3, *(1)}$, Yui Namioka ${ }^{3}$, Haidar Rafid Azis ${ }^{2}$, Tomoharu Sano ${ }^{4}$, Mitsuko Aono ${ }^{3,5}$, \\ Masami Koshiyama ${ }^{6}$, Hiroshi Fujisawa ${ }^{7}$ and Hiroko Isoda $1,2,3$ (D) \\ 1 Faculty of Life and Environmental Sciences, University of Tsukuba, Tsukuba 305-8572, Japan \\ 2 Alliance for Research on the Mediterranean and North Africa (ARENA), University of Tsukuba, \\ Tsukuba 305-8572, Japan \\ 3 Master's Program in Life Science Innovation (T-LSI), University of Tsukuba, Tsukuba 305-8572, Japan \\ 4 Health and Environmental Risk Division, National Institute for Environmental Studies, \\ Tsukuba 305-8506, Japan \\ 5 Biodiversity Division, National Institute for Environmental Studies, Tsukuba 305-8506, Japan \\ 6 Specialty Chemicals Division, Zeon Corporation, Chiyoda, Tokyo 104-8246, Japan \\ 7 Headquarters, Zeon Corporation, Chiyoda, Tokyo 104-8246, Japan \\ * Correspondence: takahashi.shinya.fp@u.tsukuba.ac.jp
}

Citation: Takahashi, S.; Namioka, Y.; Azis, H.R.; Sano, T.; Aono, M.; Koshiyama, M.; Fujisawa, H.; Isoda, H. Prohydrojasmon Promotes the Accumulation of Phenolic Compounds in Red Leaf Lettuce. Plants 2021, 10, 1920. https:// doi.org/10.3390/plants10091920

Academic Editor: Cecilia Cagliero

Received: 27 July 2021

Accepted: 13 September 2021

Published: 15 September 2021

Publisher's Note: MDPI stays neutral with regard to jurisdictional claims in published maps and institutional affiliations.

Copyright: (c) 2021 by the authors. Licensee MDPI, Basel, Switzerland. This article is an open access article distributed under the terms and conditions of the Creative Commons Attribution (CC BY) license (https:// creativecommons.org/licenses/by/ $4.0 /)$.

\begin{abstract}
Prohydrojasmon (PDJ) is a synthetic jasmonate derivative that is primarily used as a growth regulator, but its mechanism of action is unclear. In this study, we elucidated the effects of PDJ on phytochemical production in red leaf lettuce. The PDJ treatments promoted the accumulation of phenolic compounds in aerial plant parts. An LC-MS analysis revealed that these accumulated compounds were identified as cyanidin-3-O-glucoside, cyanidin-3-O-(6"-O-malonyl)-glucoside and cyanidin-3-O-(6"-O-malonyl)-glucoside methyl ester. The abundance of these compounds in lettuce extracts increased significantly in response to the PDJ treatment. Additionally, the LC-MS analysis also identified the accumulated phenolic compounds in the extracts of PDJ-treated lettuce, including caffeoyltartaric acid, chlorogenic acid, caffeoylmalic acid, chicoric acid, and dicaffeoylquinic acid. Gene expression analyses indicated the PDJ treatments upregulated the expression of $P A L, F 3 H$, and ANS genes in lettuce. These results suggest that PDJ treatments enhance the expression of genes involved in the synthesis of anthocyanins and phenolic compounds, resulting in an increase in the quantities of these compounds, which reportedly have various functions affecting human physiology.
\end{abstract}

Keywords: anthocyanin; jasmonate; prohydrojasmon; phenolic acid; red leaf lettuce

\section{Introduction}

The demand for foods rich in phytochemicals has recently increased [1]. There is considerable epidemiological evidence that polyphenols promote health and decrease the risk of various diseases, including cancers and cardiovascular diseases [2,3]. Diverse vegetables and fruits are sources of polyphenols, and diets rich in polyphenols can help protect against several diseases $[4,5]$.

Lettuce is a popular vegetable included in various foods to enhance human health. Its health-promoting properties are associated with its substantial abundance of antioxidants, primarily vitamin $C$ and polyphenols, and fiber [6]. A previous study involving humans and rats revealed the protective effects of lettuce against cardiovascular diseases [7]. In red leaf lettuce (Lactuca sativa L.), quercetin, luteolin, cyanidin, chicoric acid, and caffeoylmalic acid are the major phytochemicals [8]. Phytochemical production in lettuce increases in response to environmental stresses, such as ultraviolet radiation, as well as injuries and postharvest processing [9].

Enhancing flavonoid biosynthesis pathways by modulating environmental conditions may be useful for promoting phytochemical production in crops. For example, cultivating 
lettuce plants in a greenhouse under low-temperature conditions reportedly induces the production of some types of phytochemicals [10]. Recent studies examined the utility of high-intensity artificial light, such as light-emitting diodes or ultraviolet light sources, for increasing lettuce anthocyanin contents [11,12]. Some genes encoding key enzymes in the phenylpropanoid pathway, including phenylalanine ammonia-lyase (PAL) and chalcone synthase (CHS), are light-inducible genes [13-15]. Additionally, some genes affecting anthocyanin synthesis pathways, including those encoding dihydroflavonol 4reductase (DFR), leucoanthocyanidin dioxygenase (LDOX), and UDP-glucose: flavonoid 3-O-glucosyltransferase (UFGT), are jasmonic acid (JA)-inducible genes regulated by the phytochrome-mediated pathway in Arabidopsis [16].

Although altering light conditions is a convenient way to promote crop growth and phytochemical production during commercial crop production, installing new equipment and the associated power consumption may increase crop production costs.

Jasmonic acid and its derivatives are plant hormones and/or plant growth regulators in higher plants that control fruit ripening and coloration (including pigment accumulation). They can also induce the biosynthesis of secondary compounds, including phenylpropanoid derivatives, caffeic acids, flavonols, and anthocyanins [17,18]. Moreover, JA can improve crop quality by increasing secondary metabolite contents.

Prohydrojasmon [propyl (1RS,2RS)-(3-oxo-2-pentylcyclopentyl) acetate] (PDJ) is a synthetic JA analog. Earlier research proved that PDJ functions mimic those of JA in plants [19-21]. The use of PDJ as a plant growth regulator remains focused on fruits, including apples, oranges, mangoes, and grapes [20,22-24]. Specifically, it has been applied to enhance mango and red pear fruit coloration $[25,26]$. In our study, lettuce and komatsuna grown under artificial light were treated with several PDJ concentrations, which enhanced the production of some phenolics, polyphenols, and anthocyanins in lettuce leaves [27]. However, the precise mechanisms underlying PDJ-induced phenolic production in red leaf lettuce remain unclear.

In this study, we evaluated the effects of PDJ treatments on production of phenolic compounds in hydroponically grown red leaf lettuce. Red leaf lettuce (Lettuce) plants were cultivated in PDJ-supplemented culture media. We also quantitatively analyzed the components of methanolic extracts from PDJ-treated lettuce plants via colorimetric assays and high-performance liquid chromatography (HPLC). Furthermore, we investigated the compounds and molecular mechanisms in lettuce affected by PDJ using liquid chromatography-mass spectrometry (LC-MS)-based methods to identify the unknown compounds. We conducted gene expression analyses to clarify the regulation of enzymes involved in the phenylpropanoid derivative synthesis pathway in PDJ-treated lettuce.

\section{Results}

\subsection{PDJ Treatments Increase the Phenolics Contents in Aerial Parts of Lettuce Plant}

Lettuce plants were grown hydroponically for 14 days after sowing and PDJ was supplied by irrigation for another 2 days. The first and second leaves were seen on the 16th day after sowing. The PDJ-treated lettuce showed red color compared to the lettuce without PDJ treatment (Supplementary Figure S1). We determined the contents of metabolites in the extracts from the aerial parts of lettuce plants treated with 0,100 or $200 \mu \mathrm{M}$ PDJ by measuring the absorbance at 540 and $305 \mathrm{~nm}$. The metabolites absorbed at $540 \mathrm{~nm}$ containing the anthocyanin, were, respectively, 2.7-and 4.2-times higher in the lettuce plants treated with 100 and $200 \mu \mathrm{M}$ than in the control plants (Figure 1A). The metabolites absorbed at $305 \mathrm{~nm}$ containing UV-light absorbing pigments (i.e., caffeic acid and flavonoid derivatives) were, respectively, 1.6- and 2.3-times higher in the lettuce plants treated with 100 and $200 \mu \mathrm{M}$ than in the control plants (Figure 1B). We also determined the total phenolic content of the extracts from the aerial parts of lettuce plants treated with 0,100 or $200 \mu \mathrm{M}$ PDJ. Total phenolic content was 1.3-and 2.2-times greater in the lettuce plants treated with 100 and $200 \mu \mathrm{M}$ PDJ than in the control plants, respectively (Figure 1C). 
(A)

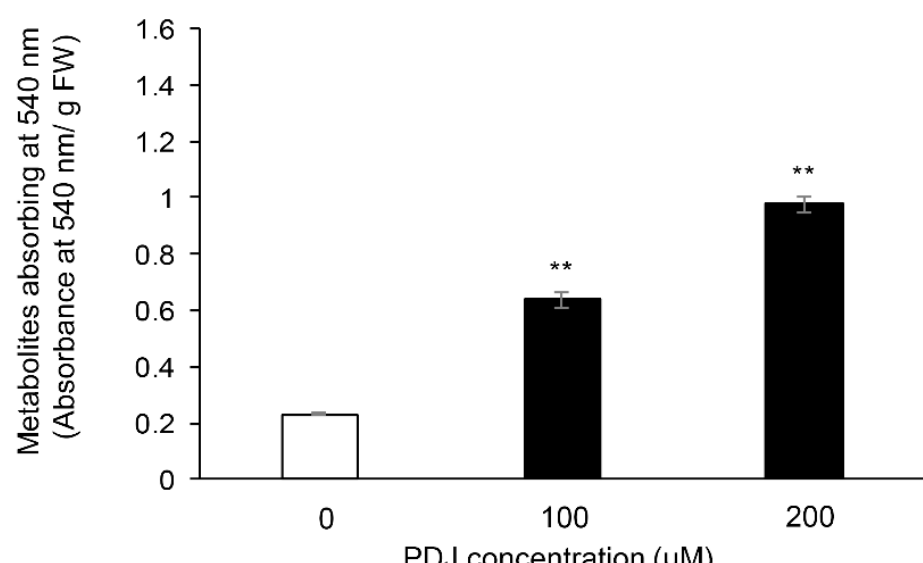

(B)

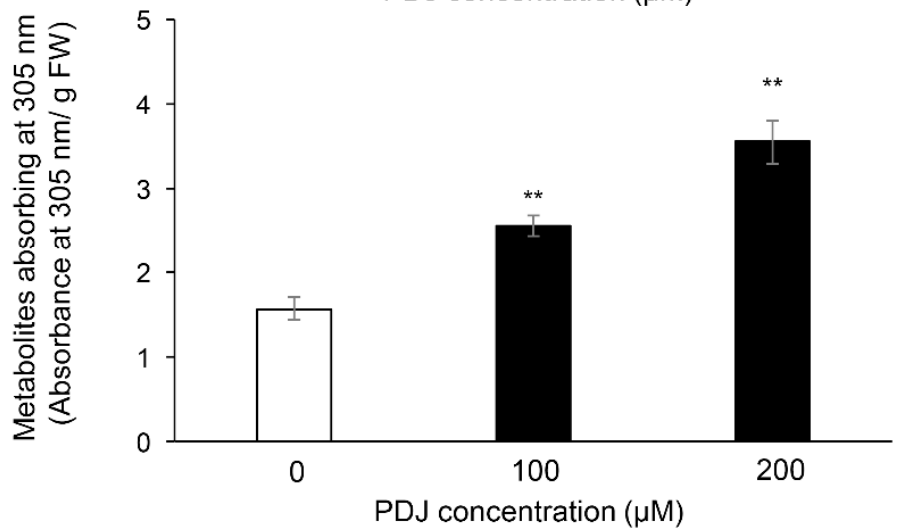

(C)

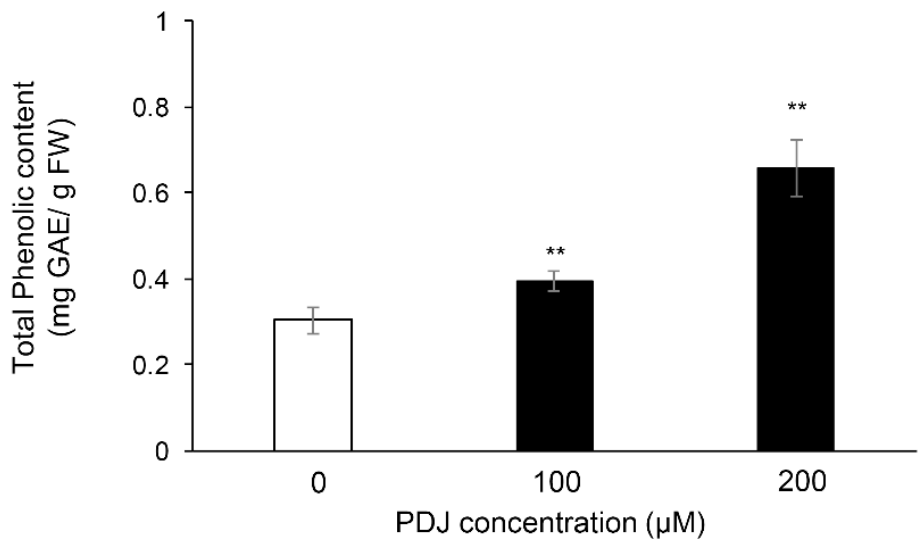

Figure 1. Amounts of compounds in extracts from aerial parts of PDJ-treated lettuce plant. Extracts from aerial parts of plants treated with (black) or without (white) $100 \mu \mathrm{M}$ or $200 \mu \mathrm{M}$ PDJ were measured the absorbance at $540 \mathrm{~nm}(A)$ and $305 \mathrm{~nm}$ (B). The extracts were reacted with phenolic reagents $(C)$, for measurement of total phenolic content, measured the absorbance at $750 \mathrm{~nm}$, respectively. Each value was calibrated with the fresh weight of the aerial parts. Each value indicated as mean \pm standard error. Statistically significant differences are indicated by an asterisk $\left({ }^{* *} p<0.01\right)$.

\subsection{Extracts of PDJ-Treated Lettuce Plants Increased in Antioxidant Activities}

We conducted the DPPH radical scavenging assay to measure the antioxidant activities of the lettuce extracts. DPPH radical scavenging activities of the extracts from lettuce plants treated with $200 \mu \mathrm{M}$ PDJ were higher than that of the control plants (Figure 2). 


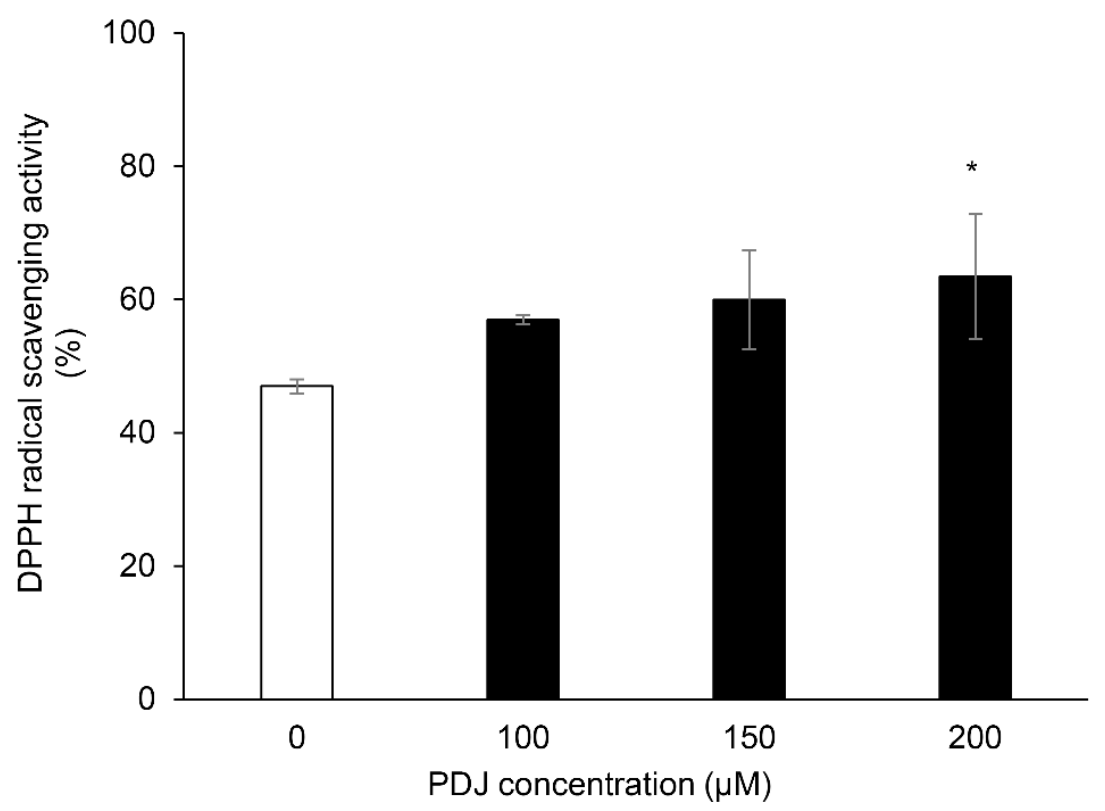

Figure 2. Radical scavenging activity in extracts from aerial parts of PDJ-treated lettuce plant. Extracts from aerial parts of plants treated with (black) or without (white) 100, 150, or $200 \mu$ M PDJ were reacted with DPPH reagents, for radical scavenging activity, and then measured the absorbance at 520 $\mathrm{nm}$, respectively. Each value indicated as mean \pm standard error. Statistically significant differences are indicated by an asterisk $\left({ }^{*} p<0.05\right)$.

\subsection{Quantification and Identification of the Pheolics in the Leaf Extracts from Lettuce Plants Treated with PDI}

To clarify the changes to phenolics in PDJ-treated lettuce plants, we analyzed the extracts from the aerial parts of lettuce plants at 2 days after the PDJ treatment using an HPLC system. The chromatograms (at $520 \mathrm{~nm}$ ) for the anthocyanins in the extracts from lettuce plants treated with 100 and $200 \mu \mathrm{M}$ PDJ included three peaks (Figure 3).

The anthocyanins with increased contents induced by the PDJ treatments were analyzed by LC-MS. We determined all three peaks in Figure 3 from the LC-PDA-MS analysis data (Supplementary Figures S2-S6) comparing with the data of the literature. On the basis of an analysis of the mass spectra, the peaks at retention times of 5.97, 7.70, and $8.72 \mathrm{~min}$ were assigned to cyanidin-3-O-glucoside (Cy3G; $\mathrm{M}+, 449 \mathrm{~m} / \mathrm{z})$, cyanidin-3-O-(6"$\mathrm{O}$-malonyl)-glucoside (Cy3MG; $\mathrm{M}+, 535 \mathrm{~m} / \mathrm{z})$, and cyanidin-3-O-(6"-O-malonyl)-glucoside methyl ester (Cy3MG-Me; M+, $549 \mathrm{~m} / \mathrm{z}$ ), respectively, on the basis of the mass spectra, UV-vis spectra, and previous reports [28-31]. One of the three peaks was detected at the same retention time as the standard compound for cyanidin-3-O-glucoside using the HPLC system (Figure $\mathrm{S} 7$ ).

The Cy3G content of the PDJ-treated lettuce increased 2.5-and 6.39-times in responses to the 100 and $200 \mu \mathrm{M}$ PDJ treatment, respectively. The Cy3MG content of the PDJtreated lettuce increased 2.31- and 10.5-times in responses to the 100 and $200 \mu \mathrm{M}$ PDJ treatment, respectively. The Cy3MG-Me content of the PDJ-treated lettuce increased 1.95and 8.05-times in responses to the 100 and $200 \mu \mathrm{M}$ PDJ treatment, respectively (Table 1 and Figure 3). 
(A)

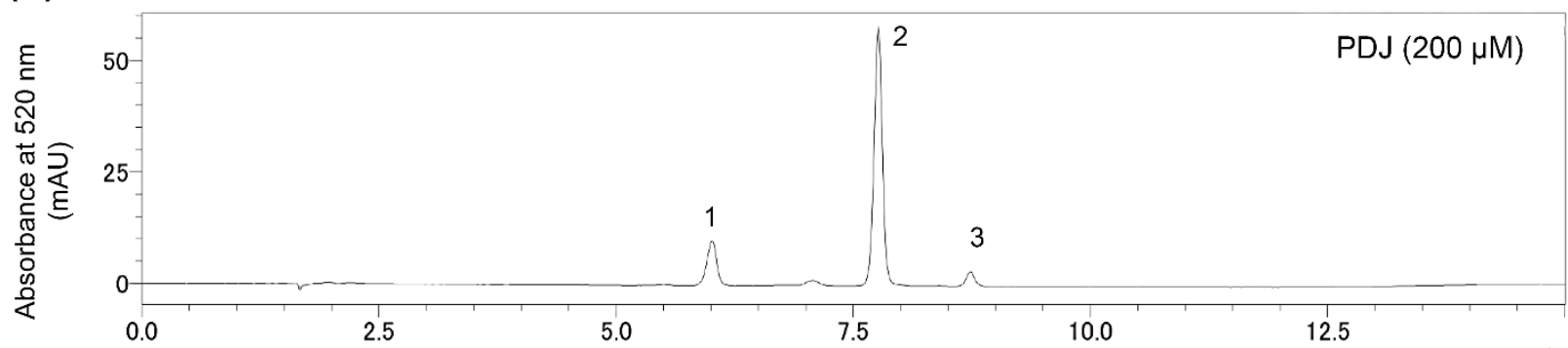

(B)

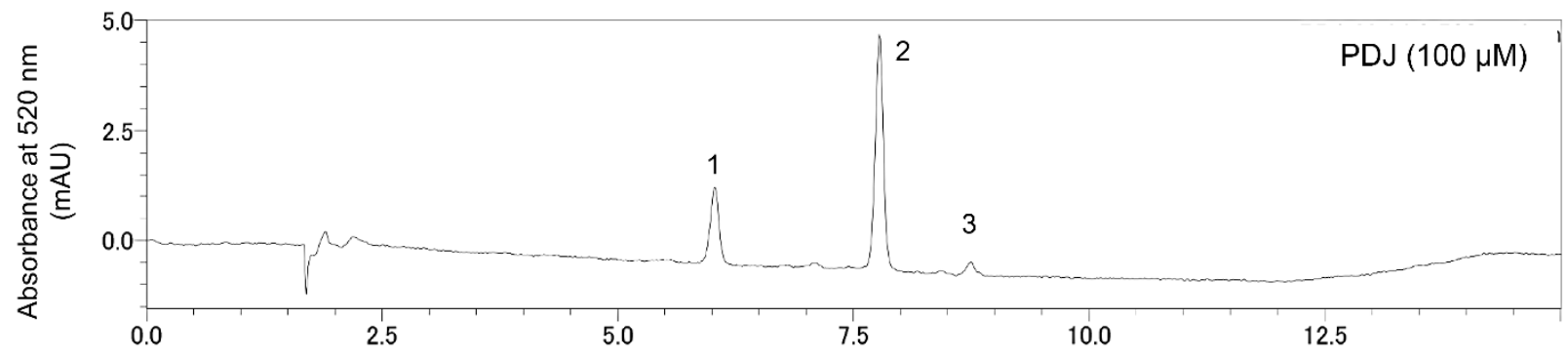

(C)

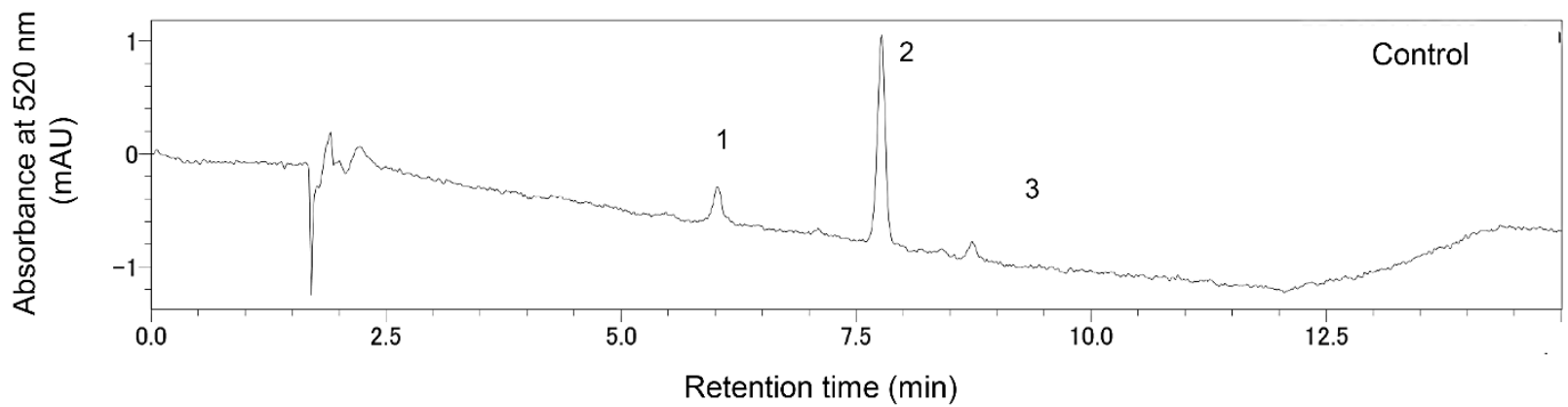

Figure 3. Chromatogram of compounds from the lettuce plant treated with PDJ obtained. Extracts from aerial parts of plants treated with $200 \mu \mathrm{M}$ PDJ (A), $100 \mu \mathrm{M}$ PDJ (B) or without (C) PDJ were analyzed by the HPLC method. Heights of the peak were indicated as absorbance at $520 \mathrm{~nm}$ (mAU). Peak1: cyanidin-3-O-glucoside (Cy3G), Peak2: cyanidin-3-O-(6"'-Omalonyl)-glucoside (Cy3MG), and Peak3: cyanidin-3-O-(6"-O-malonyl)-glucoside methyl ester (Cy3MG-Me).

Table 1. Contents of individual anthocyanin derivatives in lettuce leaves after PDJ treatments.

\begin{tabular}{|c|c|c|c|c|c|c|}
\hline \multirow{2}{*}{ Compound } & \multirow{2}{*}{ Rt (min) } & \multirow{2}{*}{$\begin{array}{c}\lambda \max \\
(\mathrm{nm})\end{array}$} & \multirow{2}{*}{$\begin{array}{l}\mathrm{M}+ \\
m / z\end{array}$} & \multicolumn{3}{|c|}{$\begin{array}{c}\text { Content [ } \mu \text { g Cy3G eq./g Fresh Weight] } \\
\text { (Mean } \pm \text { SD) }\end{array}$} \\
\hline & & & & $0 \mu \mathbf{M}$ & $100 \mu \mathrm{M}$ & $200 \mu \mathrm{M}$ \\
\hline Сy3G & 5.97 & 273,520 & 449 & $1.66 \pm 1.54^{\mathrm{c}}$ & $4.19 \pm 0.66^{b}$ & $10.6 \pm 0.2^{a}$ \\
\hline Су3MG & 7.70 & 277,519 & 535 & $2.43 \pm 0.04^{c}$ & $5.62 \pm 0.02^{b}$ & $25.6 \pm 0.4^{a}$ \\
\hline Су3MG-Me & 8.72 & 270,523 & 549 & $0.64 \pm 0.02^{c}$ & $1.25 \pm 0.08^{b}$ & $5.15 \pm 0.08^{a}$ \\
\hline
\end{tabular}

Rt: retention time; Cy3G: cyanidin-3-O-glucoside; Cy3MG: cyanidin-3-O-(6"-O-malonyl)-glucoside; Cy3MGMe: Cyanidin-3-O- $\left(6^{\prime \prime}-\mathrm{O}\right.$-malonyl)-glucoside methyl ester. Significant different letters $\left.{ }^{\mathrm{a}-\mathrm{C}}\right)$ in the same row are indicated by different superscript letters $(p<0.05)$.

The chromatograms (at $325 \mathrm{~nm}$ ) for the phenolics in the extracts from lettuce plants treated with 100 and $200 \mu \mathrm{M}$ PDJ (Figure 4 and Table 2) comprised six peaks. 


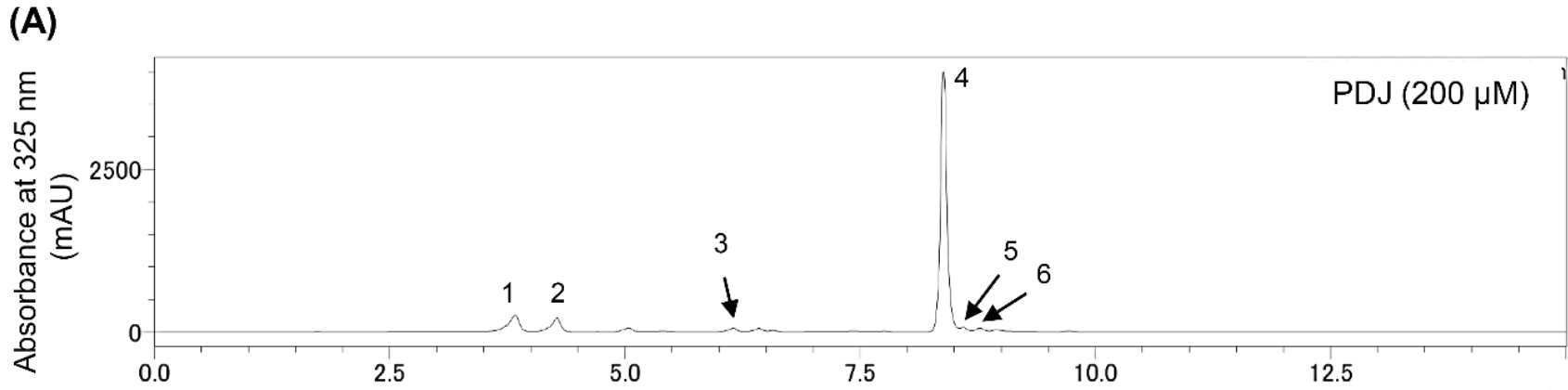

(B)

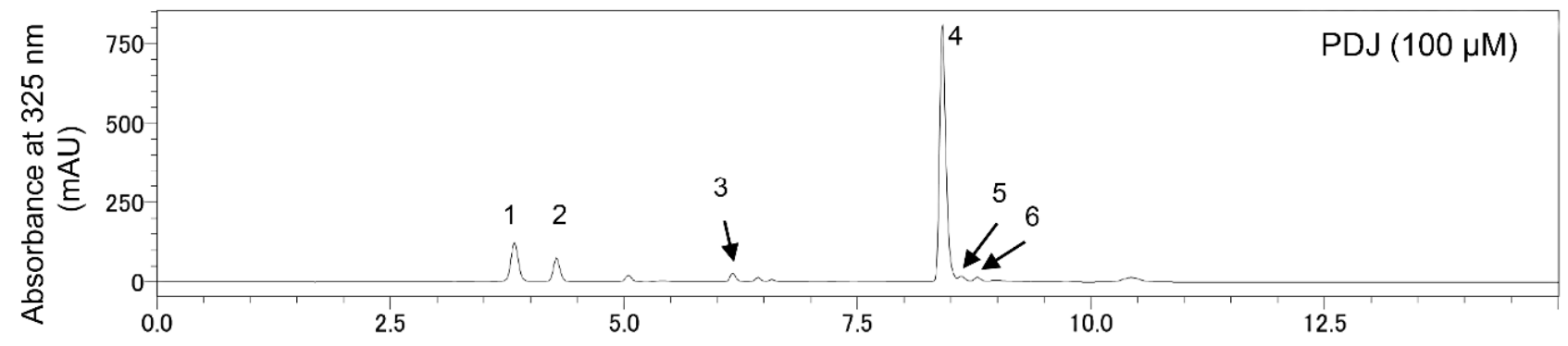

(C)

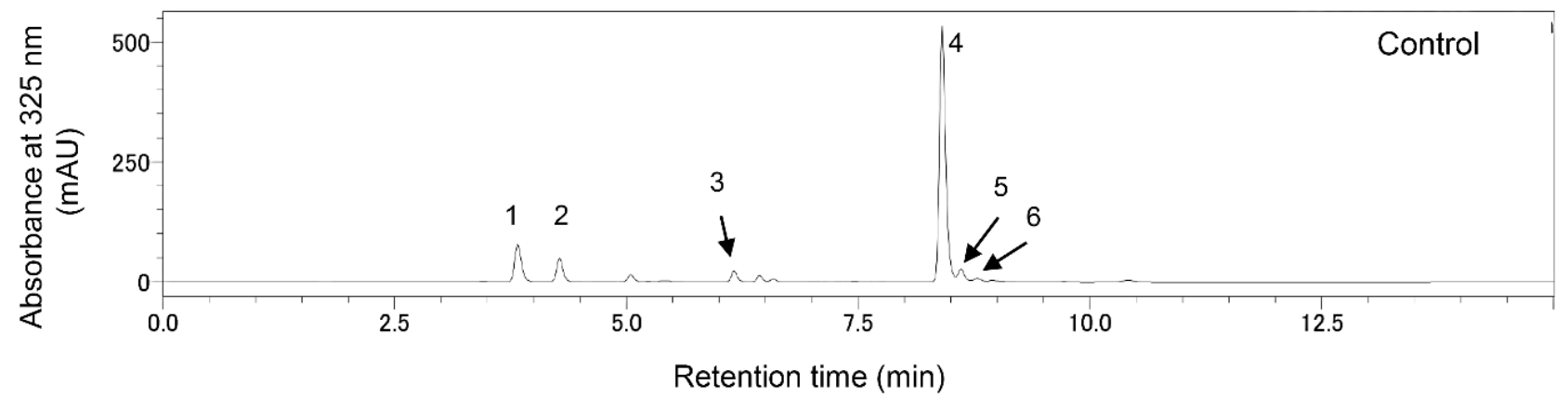

Figure 4. Chromatogram of compounds from the lettuce plant treated with PDJ obtained. Extracts from aerial parts of plants treated with $200 \mu \mathrm{M}$ PDJ (A), $100 \mu \mathrm{M}$ PDJ (B) or without (C) PDJ were analyzed by the HPLC method. Heights of the peak were indicated as absorbance at $325 \mathrm{~nm}$ (mAU). Peak1: caffeoyltartaric acid (CTA), Peak2: chlorogenic acid, Peak3: caffeoylmalic acid (CMA), Peak4: chicoric acid, Peak5: dicaffeoylquinic acid (diCQA), and Peak6: unidentified compound.

Table 2. Contents of caffeic acid derivatives in lettuce leaves after PDJ treatments.

\begin{tabular}{|c|c|c|c|c|c|c|}
\hline \multirow{2}{*}{ Compound } & \multirow{2}{*}{ Rt (min) } & \multirow{2}{*}{$\begin{array}{c}\text { UV } \\
\lambda \max \\
(\mathrm{nm})\end{array}$} & \multirow{2}{*}{$\begin{array}{l}{[\mathbf{M}-\mathbf{H}]^{-}} \\
\quad m / z\end{array}$} & \multicolumn{3}{|c|}{$\begin{array}{l}\text { Content [mg Chicoric Acid eq./g Fresh Weight] } \\
\text { (Mean } \pm \text { SD) }\end{array}$} \\
\hline & & & & $\mathbf{0} \mu \mathbf{M}$ & $100 \mu \mathrm{M}$ & $200 \mu \mathrm{M}$ \\
\hline CTA & 3.73 & 329 & 311 & $0.114 \pm 0.001^{\mathrm{c}}$ & $0.137 \pm 0.002^{b}$ & $0.428 \pm 0.005^{\mathrm{a}}$ \\
\hline Chlorogenic acid & 4.41 & 326 & 353 & $0.059 \pm 0.0003^{c}$ & $0.069 \pm 0.001^{b}$ & $0.269 \pm 0.006^{\mathrm{a}}$ \\
\hline $\mathrm{CMA}$ & 6.12 & 328 & 295 & $0.038 \pm 0.001^{\mathrm{c}}$ & $0.033 \pm 0.0001^{b}$ & $0.121 \pm 0.002^{\mathrm{a}}$ \\
\hline Chicoric acid & 8.34 & 329 & 473 & $0.731 \pm 0.028^{c}$ & $0.795 \pm 0.015^{b}$ & $2.824 \pm 0.025^{\mathrm{a}}$ \\
\hline diCQA & 8.78 & 327 & 515 & $0.030 \pm 0.001^{\mathrm{c}}$ & $0.023 \pm 0.001^{b}$ & $0.077 \pm 0.001^{\mathrm{a}}$ \\
\hline
\end{tabular}

Rt: retention time; CTA: caffeoyltartaric acid; CMA: caffeoylmalic acid; diCQA: dicaffeoylquinic acid. Significant different letters $\left.{ }^{(\mathrm{a}-\mathrm{c}}\right)$ in the same row are indicated by different superscript letters $(p<0.05)$.

We determined all six peaks in Figure 4 from the LC-PDA-MS analysis data (Supplementary Figures S2-S6) comparing with the data of the literature [8,32-37]. Specifically, the peaks at retention times of $3.73,4.41,6.12,8.34,8.78$, and 8.94 min were assigned to caffeoyltartaric acid (CTA; $\left.[\mathrm{M}-\mathrm{H}]^{-}, 311 \mathrm{~m} / z\right)$, chlorogenic acid $\left([\mathrm{M}-\mathrm{H}]^{-}, 353 \mathrm{~m} / z\right)$, caf- 
feoylmalic acid (CMA; [M - H] $]^{-}, 295 \mathrm{~m} / \mathrm{z}$ ), 2,3-dicaffeoyltartaric (chicoric) acid (2,3-diCTA; $[\mathrm{M}-\mathrm{H}]^{-}, 473 \mathrm{~m} / z$ ), and dicaffeoylquinic acid (diCQA; [M $\left.-\mathrm{H}\right]^{-}, 515 \mathrm{~m} / \mathrm{z}$ ), respectively, on the basis of the mass spectra, UV spectra and previous reports [34,38,39]. It was suggested that peak 6 in Figure 4 may be the quercetin-3-O-(6"-O-malonyl)-glucoside (Q3MG; $\left.[\mathrm{M}-\mathrm{H}]^{-}, 549 \mathrm{~m} / z\right)$ from the mass spectra and previous reports $[34,38,39]$. However, since no further evaluation data were available, we could not be identified as the Q3MG. Two of the six peaks were detected at the same retention times as each of the standard compounds for chlorogenic acid and chicoric acid using the HPLC system (Supplementary Figure S8).

The chicoric acid content increased 1.09- and 3.86-times in response to the 100 and $200 \mu \mathrm{M}$ PDJ treatment, respectively. The content of CTA was 1.2- and 3.75 times higher in the extracts from lettuce plants treated with 100 and $200 \mu \mathrm{M}$ PDJ, respectively, than in the control extract. The chlorogenic acid contents increased 1.17- and 4.56-times in response to the 100 and $200 \mu \mathrm{M}$ PDJ treatment, respectively. The CMA contents increased 0.87 - and 3.18-times in response to the 100 and $200 \mu \mathrm{M}$ PDJ treatment, respectively. The diCQA contents increased 0.77-and 2.56-times in response to the 100 and $200 \mu \mathrm{M}$ PDJ treatment, respectively (Table 2 and Figure 4).

\subsection{Expression Analysis of Lettuce Genes Involved in the Phenylpropanoid Derivative Synthesis Pathway in PDJ-Treated Lettuce}

We detected an increase in the contents of several anthocyanins and phenolic acids in PDJ-treated lettuce plants. In previous studies, some lettuce genes in the phenylpropanoid synthesis pathway were identified and investigated [11,40]. To clarify the mechanisms in lettuce affected by PDJ treatments, we analyzed the PDJ-induced gene expression changes in lettuce plants. We observed a slight difference in the degree of red color between the first and second leaf in the lettuce plantlets (Figure S1). Therefore, we determined the PDJ-induced gene expression changes in the first and second leaf of the lettuce aerial parts.

We selected the following six genes for a quantitative real-time PCR (qPCR) analysis: phenylalanine ammonia-lyase $(P A L)$, chalcone synthase $(C H S)$, flavanone 3-hydroxylase $(F 3 H)$, flavonol synthase (FLS), dihydroflavonol 4-reductase (DFR), anthocyanidin synthase (ANS), and UDP-glucose: flavonoid 3-O-glucosyltransferase (UFGT). These genes encode key enzymes in the phenylpropanoid derivative synthesis pathway in lettuce [11].

At $48 \mathrm{~h}$ after the PDJ treatment, the expression of most of the analyzed genes was upregulated in the first and second leaves of PDJ-treated lettuce plants. In the first leaf, the PAL (2.5-times), F3H (8.75-times), DFR (2.62-times), and ANS (2.89-times) expression levels were higher in the PDJ-treated lettuce plants than in the control plants, although the difference was significant only for PAL and F3H. Additionally, the UFGT expression level (3.29-times) also tended to be higher in PDJ-treated lettuce, relative to the control level (Figure 5). In the second leaf, the PAL (1.93-times), F3H (1.95-times), DFR (7.3-times), and ANS (5.04-times) genes tended to be more highly expressed in the PDJ-treated lettuce plants than in the control plants, but the difference was significant only for ANS (Figure 6). In contrast, there were no differences in the $C H S$ expression levels between the PDJ-treated and control plants. These results suggested that the genes induced by the PDJ treatment influenced lettuce plant metabolism and promoted the production of caffeic acid derivatives and anthocyanin derivatives within $48 \mathrm{~h}$. 
(A)
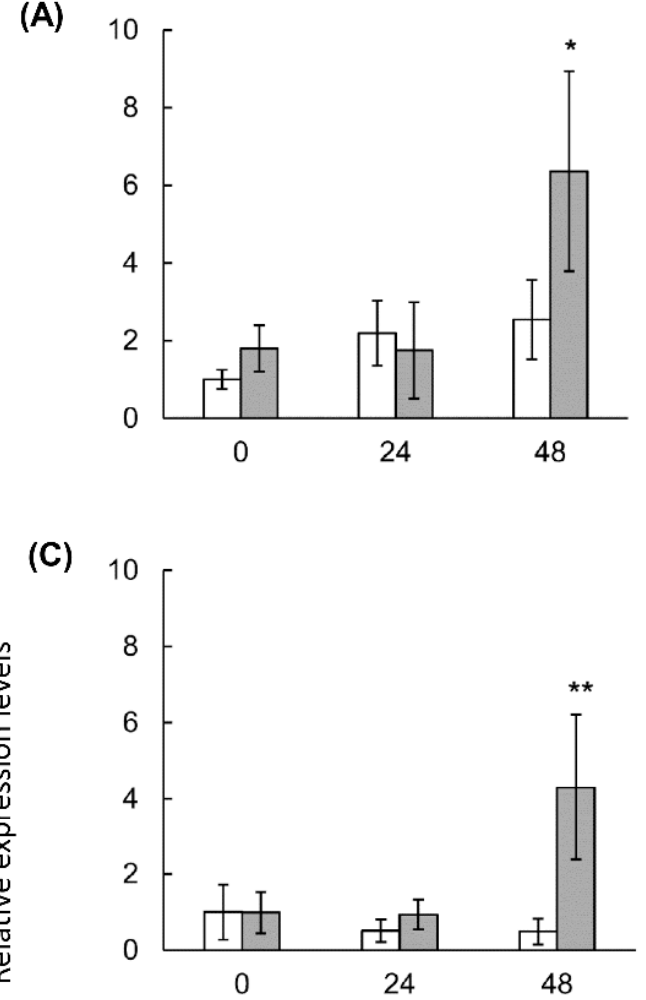

(E)

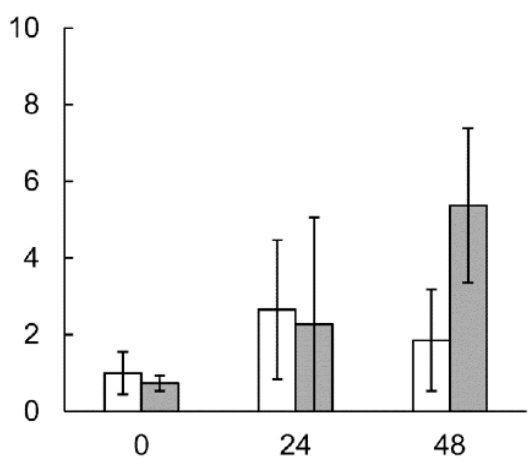

(B)

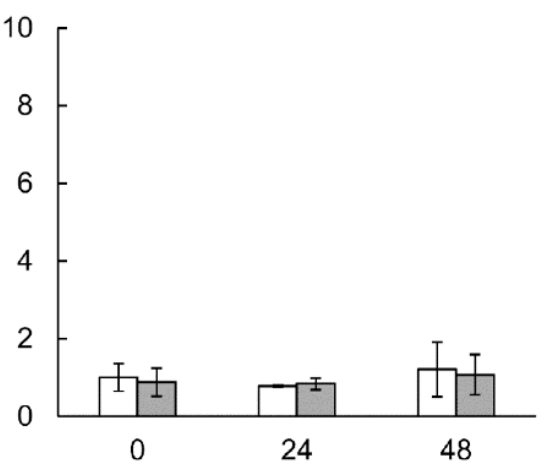

(D)

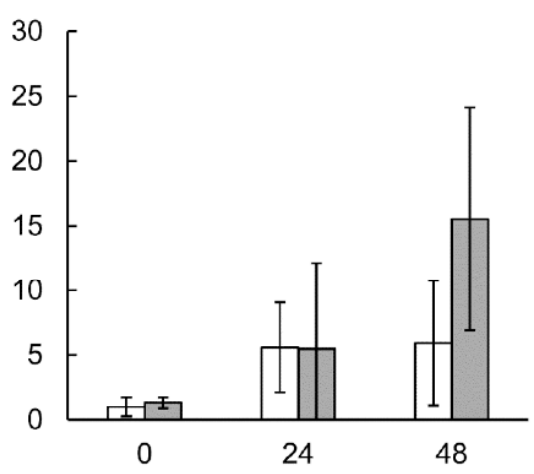

(F) 10

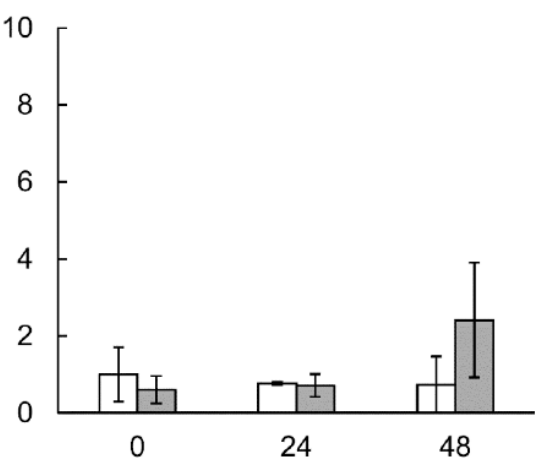

Time after PDJ treatment $(\mathrm{h})$

Figure 5. Gene expression of phenylpropanoid derivatives pathway in first leaves of lettuce plants treated with PDJ. The figure is 0 and $48 \mathrm{~h}$ after treatment. Gene-specific primer sets of PAL (A), CHS (B), F3H (C), DFR (D), ANS (E), and UFGT (F) were used to detect each gene expression by qPCR. Each value indicated as the average of relative expression three times using RNA samples obtained from three independent experiments. Statistically significant differences are indicated by an asterisk (* or ${ }^{* *}$ indicate $p<0.05$ or 0.01 , respectively). 
(A)
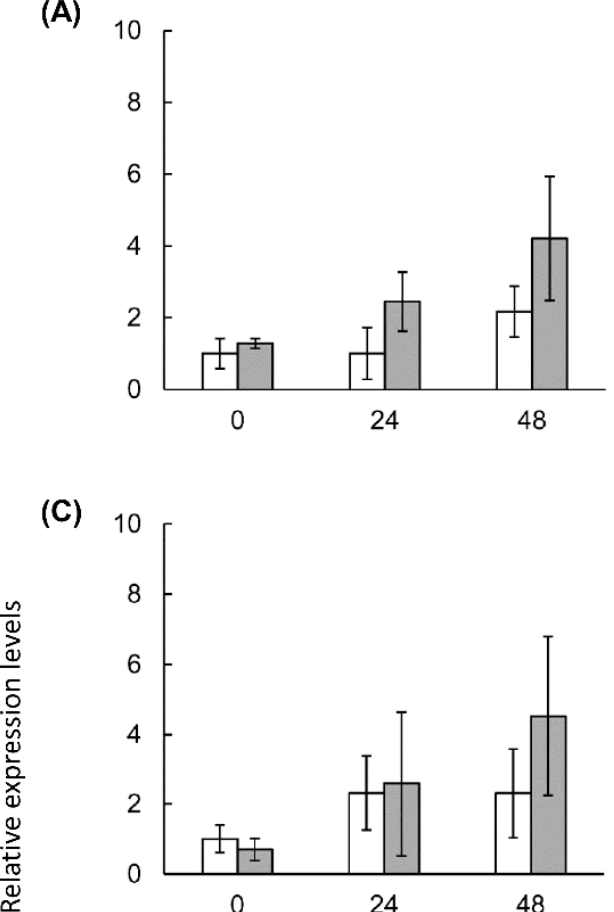

(E)

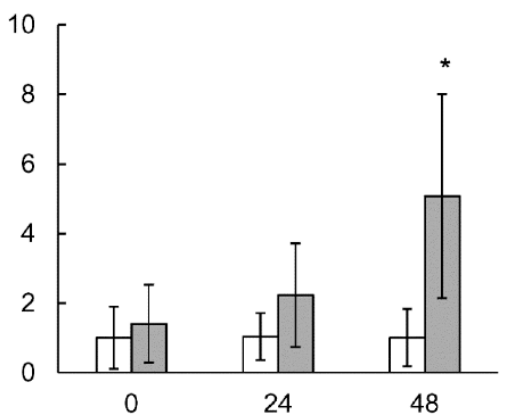

(B)

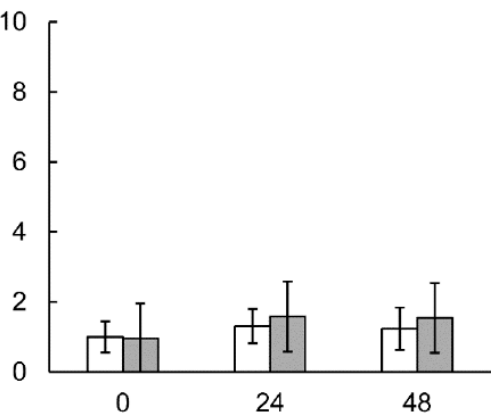

(D)

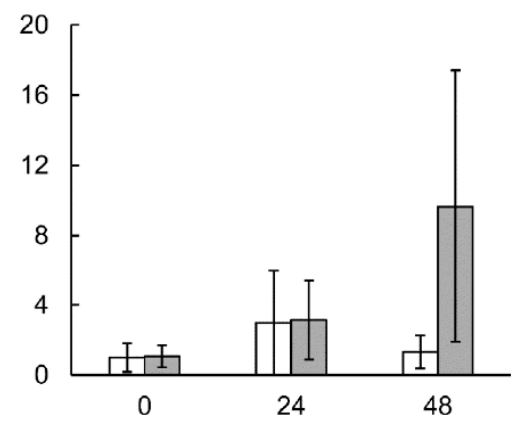

(F)

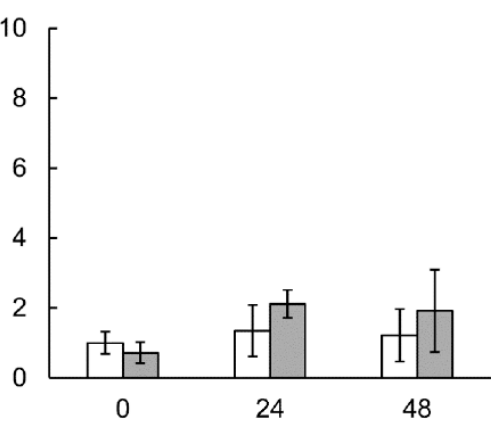

Time after PDJ treatment (h)

Figure 6. Gene expression of phenylpropanoid derivatives pathway in second leaves of lettuce plants treated with PDJ. The second leaves of the lettuce plant with (black) or without (white) PDJ were harvested at 0,24 , and $48 \mathrm{~h}$ after treatment. Gene-specific primer sets of PAL (A), CHS (B), F3H (C), DFR (D), ANS (E), and UFGT (F) were used to detect each gene expression by qPCR. Each value indicated as the average of relative expression three times using RNA samples obtained from three independent experiments. Statistically significant differences $(p<0.05)$ are indicated by an asterisk $(*)$.

\section{Discussion}

Prohydrojasmon, which is a synthetic JA derivative, has been used as a bio-stimulant to increase anthocyanin accumulation in crops [27]. Although PDJ is commercially available as a plant growth regulator useful for enhancing the coloration of various fruits, such as apple and grape, its mechanism of action has not been comprehensively characterized. Thus, in this study, we clarified its effects using leaves from hydroponically grown lettuce plants. In our preliminary experiments, we detected significant increases in the metabolites absorbing at 305 and $540 \mathrm{~nm}$ and the total phenolic content in the first and second leaf of lettuce plants at 1, and 2 days after a $200 \mu \mathrm{M}$ PDJ treatment, especially in the first and second leaf at 2 days after the treatment (data not shown). Significant increases in the metabolites absorbing at 305 and $540 \mathrm{~nm}$ and the total phenolic content were detected 
in the lettuce plants treated with $100 \mu \mathrm{M}$ PDJ, but they were lower than that of $200 \mu \mathrm{M}$ PDJ treatment and no significant difference in the antioxidant activity at the $100 \mu \mathrm{M}$ PDJ treatment. These differences between 100 and $200 \mu \mathrm{M}$ PDJ may depend on the amounts of these compounds.

In this study, Cy3MG was the most abundant anthocyanin following the PDJ treatment. This anthocyanin is synthesized via the malonylation of Cy3G by anthocyanin 3-malonyl transferase [41].

We identified some malonylated compounds in the current study (e.g., Cy3MG). Malonylation enables the storage of phenolic compounds in vacuoles because it leads to increased water solubility and helps to stabilize the labile structure, which is conducive to the transport of compounds into the vacuole [42]. After entering cells, naphthol is mainly accumulated as a malonylglucoside, and some of it is released from cells in a methoxylated form and as a glycoside [42]. A treatment with PDJ may promote the malonylation of compounds, which are then transported and stored in vacuoles. Earlier investigations proved that Cy3MG can function as a superoxide scavenger [43] and that red leaf lettuce plants cultivated under cool conditions accumulate Cy3MG [44]. Because JA is a stressinducible plant growth regulator, stress-induced responses may accelerate the accumulation of these malonylated compounds.

On the other hand, it was reported that the Cy3MG-Me was observed as a form of the methylated cyanidin malonylglucoside during elution of the anthocyanin with acidified $\mathrm{MeOH}[28,29]$. In this process, Cy3MG reacted with the acidified $\mathrm{MeOH}$ and then esterification formed the methyl ester of Cy3MG. Additionally, finally, it converted to cyanidin-3-O-glucoside [29]. Since we used the acidified MeOH to extract the anthocyain, a part of $\mathrm{Cy} 3 \mathrm{MG}$ might convert to the Cy3MG-Me and/or Cy3G.

CMA has the same $m / z$ that of coutaric acid (CoTA). The retention time of the CoTA was $5.72 \mathrm{~min}$. This was earlier than the retention time of 5-CQA (9.11 $\mathrm{min})$ [38]. The retention time of CMA was later (13.04 $\mathrm{min})$ than 5-CQA and CTA (3.75 $\mathrm{min})$ [38]. In the present results, peak 3 in Figure 4 showed a later retention time than chlorogenic acid. Additionally, in the UV spectrum of this compound showed, the $\lambda$ max was around 328 nm (Table 2 and Supplementary Figure S6), which was different from the $\lambda$ max of CoTA $(313 \mathrm{~nm})$ [38]. Therefore, we determined that peak 3 in Figure 4 was the CMA.

The pathways involved in the synthesis of caffeic acid derivatives, such as chicoric acid, have not been thoroughly elucidated. However, a previous study on Arabidopsis confirmed that the pathway involved in the synthesis of caffeic acid derivatives diverges from $p$-coumaryl-CoA of the phenylpropanoid derivative synthesis pathway [45]. Phenylalanine ammonia-lyase is an early and key enzyme in the phenylpropanoid derivative synthesis pathway, and functions upstream of the synthesis of $p$-coumaryl-CoA. Methyl jasmonate treatments reportedly enhance PAL activity and increase the abundance of some phenolic compounds in radish [46]. We determined that PAL gene expression in lettuce is upregulated by PDJ treatments. A methyl jasmonate treatment can promote PAL activity and the expression of the PAL gene [47]. Exogenously applied PDJ can also increase the $P A L$ gene expression level in red pear [26]. Thus, in lettuce plants, PDJ may enhance PAL expression, resulting in an increase in caffeic acid derivative contents. However, future studies regarding the regulated expression of other caffeic acid synthesis-related genes will need to clarify the PDJ-induced mechanisms.

We observed that the PAL, F3H, and ANS gene expression levels in PDJ-treated lettuce tend to increase after $48 \mathrm{~h}$. In Arabidopsis, JA upregulates the expression of the late anthocyanin biosynthesis genes [48]. In the current study, we did not detect anthocyanin and flavonol intermediates, possibly because PDJ also induced the expression of the late anthocyanin biosynthesis genes (e.g., DFR, ANS, and UFGT genes), leading to the production of anthocyanin derivatives. Regarding the ANS and DFR genes, JA promotes anthocyanin accumulation in Arabidopsis plants through the COI1 (CORONATINE INSENSITIVE 1)-JAZ (JASMONATE ZIM-DOMAIN PROTEIN) transcriptional repression of the MYB75/PAP1 (R2R3 MYELOBLASTOSIS PROTEIN 75/PRODUCTION OF ANTHOCYANIN PIGMENT 
1) transcription factors [48]. Furthermore, these transcription factors have a synergistic effect under far-red light conditions, which is mediated by the far-red light receptor phytochrome A (PHYA) [16]. A recent study indicated that endogenous JA is inactivated by a sulfotransferase (ST2a) in a process that is dependent on the PHYB-PIF pathway under low red:far-red light conditions [49]. In the present study, the artificial light sources used for our experiments emitted far-red light $(700-780 \mathrm{~nm})$. Thus, the transcriptional regulation of MYB through PHYA and COI1-JAZ as well as ST2a via the PHYB-PIF-mediated pathway may contribute to the anthocyanin accumulation in lettuce plants treated with PDJ.

In our preliminary experiments, the total phenolic content and chicoric acid contents in lettuce plants grown under low-light conditions (photosynthetic photon flux density $<90 \mu \mathrm{E}$ ) did not increase following the PDJ treatment (data not shown). These results suggest that high-intensity light is required for the production of phenolic metabolites in lettuce plants. Moreover, an exposure to PDJ may enhance the production of these compounds via the upregulated expression of the corresponding genes (Figure 7). Becker et al. reported that the contents of some flavonoids, including Cy3G and Q3MG, increase in red leaf lettuce depending on the photosynthetic photon flux density, whereas phenolic acid contents, including chicoric acid, chlorogenic acid, and caffeoylmalic acid, are influenced by the leaf developmental stage rather than the photosynthetic photon flux density [44]. In future studies, we will investigate the relationship between light intensity and PDJ effects to determine the most appropriate way to improve phytochemical production in crops.

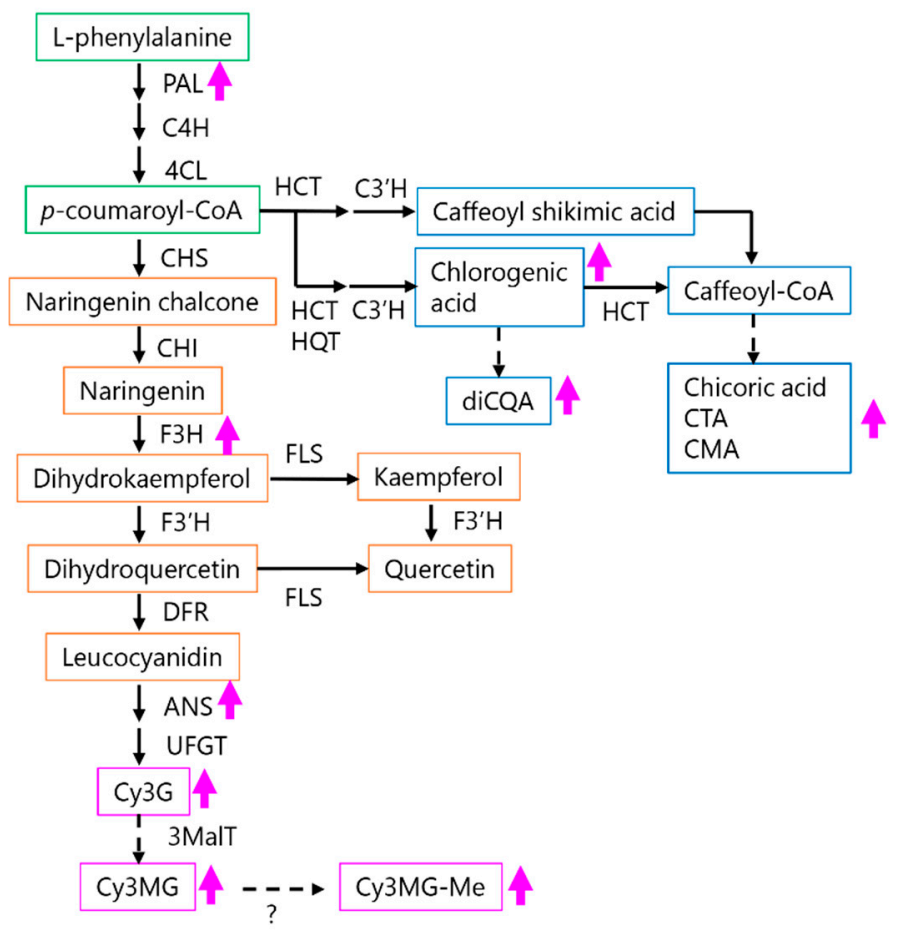

Figure 7. Predicted synthetic pathway of anthocyanin and phenolics in PDJ-treated lettuce plant. Increased amounts of compounds and expression of genes are indicated as arrows in magenta. Broken lines indicate unknown pathways. PAL: phenylalanine ammonia-lyase, CHS: chalcone synthase, CHI: chalcone isomerase, $\mathrm{F} 3 \mathrm{H}$ : flavanone 3-hydroxylase, $\mathrm{F}^{\prime}{ }^{\prime} \mathrm{H}$ : flavonoid $3^{\prime}$-hydroxylase, FLS: flavonol synthase, DFR: dihydroflavonol-4-reductase, ANS: anthocyanidin synthase, and UFGT: UDP-glucose: flavonoid 3-O-glucosyltransferase, 3MalT: anthocyanin 3-malonyl transferase, MT: anthocyanin O-methyltransferase. HCT: hydroxycinnamoyl-CoA shikimate/quinate hydroxycinnamoil transferase, $\mathrm{C}^{\prime} \mathrm{H}$ : p-coumaroyl ester $3^{\prime}$-hydroxylase, and HQT: hydroxycinnamoyl CoA quinate hydroxycinnamoyl transferase. The change from Cy3MG to Cy3MG-Me was presumed to be an artificial formation. 


\section{Materials and Methods}

\subsection{Plant Materials and Growth Conditions}

Lettuce plants (Lactuca sativa L. cv. Red-fire) were grown under hydroponic conditions. Lettuce seeds were purchased from Takii and Co. Ltd. (Kyoto, Japan). The lettuce seeds were sown and germinated and the resulting seedlings were grown on Rockwool (Grodan, Roermond, The Netherlands) moistened with tap water in a growth chamber (HD-type Koitotron, Koito-Kogyo Co., Tokyo, Japan) at the National Institute for Environmental Studies, Japan. The temperature and relative humidity were maintained at $23{ }^{\circ} \mathrm{C}$ and $60 \%$ to $70 \%$, respectively. Plants were exposed to a $14 \mathrm{~h}$ light/10-h dark cycle under fluorescent lights (National FPR96EX-N/A, Panasonic Co., Osaka, Japan) with a photosynthetic photon flux density of approximately $94 \mu \mathrm{mol} \mathrm{m}^{-2} \mathrm{~s}^{-1}$ at the top of each plant for 16 days.

\subsection{PDJ Treatments}

The lettuce seedlings were treated with a commercially available plant growth regulator, Jasmoneito Ekizai (Meiji Seika Pharma Co., Ltd., Tokyo, Japan), which contains 5\% active PDJ (equivalent to $200 \mathrm{mM}$ ). Working solutions at specific concentrations (100, 150 and $200 \mu \mathrm{M}$ ) were prepared by dilution with tap water. Regarding the control treatment, tap water containing 30\% (v/v) 1-propanol (Fujifilm-Wako Chemical Co., Osaka, Japan) and $0.03 \%(v / v)$ Tween 20 was used. At 14 days after sowing, PDJ and control solutions were supplied by irrigation only once under hydroponic conditions, and grown for another two days. For extraction of compounds absorbing at 305 and $540 \mathrm{~nm}$ and the total phenolic content, and for determination of antioxidant activity, aerial parts of lettuce plants (containing first and second leaves) were harvested 16 days after sowing. The aerial parts (fresh weight of each sample was about $0.13 \mathrm{~g}$ ) of harvested lettuce were immediately frozen in liquid nitrogen and stored at $-80^{\circ} \mathrm{C}$, after which they were lyophilized. In the aerial parts of the lettuce plant, water content was predicted about $92.7 \%$ calculated from fresh weight (just after harvested sample) and dry weight (lyophilized samples) $(n=18-20)$.

\subsection{Extraction of Phenolics from Lettuce Leaves}

Lyophilized lettuce samples (at 16 days after sowing) were ground to a powder and transferred to $15 \mathrm{~mL}$ tubes. The ground material was resuspended in a 10-fold volume of methanolic hydrochloric acid ( $80 \%$ methanol and $1 \%$ hydrochloric acid). The tubes were gently shaken to ensure the ground material was completely soaked. The tubes were incubated in darkness at $4{ }^{\circ} \mathrm{C}$ for $48 \mathrm{~h}$. The obtained extracts were used for measuring amounts of the compounds absorbing at 305 and $540 \mathrm{~nm}$ and the total phenolic content.

\subsection{Measurement of the Total Phenolic Contents of Lettuce Extracts}

The total phenolic contents were measured using the Folin-Ciocalteu (FC) reagent as previously described [27]. The FC reagent was then added and the sample was incubated in darkness for $3 \mathrm{~min}$. Next, 10\% sodium carbonate (Tokyo Kasei Industry Co. Ltd., Tokyo, Japan) was added and the sample was incubated in darkness for $30 \mathrm{~min}$. The absorbance (at $750 \mathrm{~nm}$ ) of each extract per gram fresh weight of plant tissue was measured using a microreader (Varioskan LUX, Thermo Fisher Scientific Inc., Waltham, MA, USA). The total phenolic content, which was expressed as gallic acid equivalents (GAE), was calculated based on a standard curve generated using gallic acid solutions. The data are presented herein as milligrams of gallic acid equivalents per gram of plant tissue fresh weight $(\mathrm{mg}$ GAE/g FW). The analysis was conducted three times using samples obtained from three independent experiments.

\subsection{Measurement of the Compounds Aabsorbing at 305 and $540 \mathrm{~nm}$ Contents of Lettuce Extracts}

The compounds absorbing at 305 and $540 \mathrm{~nm}$ were measured as previously described, with some modifications [27]. Briefly, the absorbance at $305 \mathrm{~nm}$ and $540 \mathrm{~nm}$ of the methanolic hydrochloric acid extracts of plant tissues (whole aerial lettuce plant parts) were measured using the Varioskan LUX microreader. Each extract was transferred to a 96-well 
microplate. The compounds absorbing at 305 and $540 \mathrm{~nm}$ contents are herein expressed as the absorbance of the extract per gram of plant tissue fresh weight (Absorbance at $305 \mathrm{~nm} / \mathrm{g}$ FW and Absorbance at $540 \mathrm{~nm} / \mathrm{g}$ FW). The analysis was conducted three times using samples obtained from three independent experiments.

\subsection{Measurement of the Antioxidant Activity of Lettuce Extracts}

The antioxidant activity was measured using the DPPH (2,2-diphenyl-1-picrylhydrazyl) free radical scavenging assay as previously described [27,34]. Briefly, a DPPH working solution was prepared and Trolox was used to generate a standard curve. A $10 \mu \mathrm{L}$ aliquot of the extract or Trolox was mixed with a $190 \mu \mathrm{L}$ DPPH working solution. The sample was added to a microplate, which was incubated in darkness for $10 \mathrm{~min}$ at ambient temperature to allow the reaction to proceed. The absorbance at $520 \mathrm{~nm}$ was measured in triplicate for each DPPH (+) and DPPH (-) sample using the Varioskan LUX microreader. The DPPH radical scavenging activity was expressed as the percentage absorbance inhibition (\%) calculated according to the following:

$$
\mathrm{DPPH} \text { radical scavenging activity }(\%)=[(\mathrm{AB}-\mathrm{AS}) / \mathrm{AB}] \times 100
$$

when AB: Absorbance of the blank; AS: Absorbance of the sample. The analysis was conducted three times using samples obtained from three independent experiments.

\subsection{HPLC and LC-MS Analyses of the Extracts from PDJ-Treated Lettuce}

The methanolic hydrochloric acid extracts were passed through filter paper (ADVANTEC, Tokyo, Japan), after which the filtrates were heated in a water bath at $40^{\circ} \mathrm{C}$ and then dried using a rotary evaporator (EYELA Tokyo Rikakikai Co. Ltd., Tokyo, Japan). The volume was adjusted with methanolic hydrochloric acid for a sample concentration of $5 \mathrm{mg} / \mathrm{mL}$. Extracts were stored at $-30^{\circ} \mathrm{C}$ until analyzed. The extracts were filtered using a $0.45 \mu \mathrm{m}$ Syringe Driven Filter (Milex-LH, Merck Millipore Ltd., Tullagreen, Ireland) for the HPLC analysis, which was completed using the Ultimate 3000 system (Thermo Fisher Scientific, Waltham, MA, USA). More specifically, the extracts were separated and analyzed using the Acclaim C30 stationary phase column (pore size $3 \mu \mathrm{m}, 3.0 \mathrm{~mm} \times 150 \mathrm{~mm}$; Thermo Fisher Scientific, Waltham, MA, USA). The mobile phases were $0.1 \%(v / v)$ trifluoroacetic acid (Fujifilm-Wako Chemical, Richmond, VA, USA) as solvent A and 100\% acetonitrile (Fujifilm-Wako Chemical) as solvent $\mathrm{B}$. The initial gradient conditions were $90 \% \mathrm{~A}$ and $10 \% \mathrm{~B}$. In $10 \mathrm{~min}$, the gradient reached $75 \% \mathrm{~A}$ and $25 \% \mathrm{~B}$. In the following $10 \mathrm{~min}$, the gradient was adjusted to $90 \% \mathrm{~A}$ and $10 \% \mathrm{~B}$. The sample injection volume was $1 \mu \mathrm{L}$. The column flow rate was $0.5 \mathrm{~mL} / \mathrm{min}$ at $30^{\circ} \mathrm{C}$. The absorbance was measured at 520 and $325 \mathrm{~nm}$ for anthocyanin and phenolic acids (hydroxycinnamic acids), respectively, using a diode array detector system (DAD-3000, Thermo Fisher Scientific, Waltham, MA, USA). As standard compounds, cyanidin-3-O-glucoside chloride (Nagara Science Co. Ltd., Gifu, Japan; purity on HPLC $\geq 99 \%$ ), chlorogenic acid (Fujifilm-Wako Chemical Co., Osaka, Japan), and chicoric acid (Tokyo Chemical Industry Co. Ltd., Tokyo, Japan; purity on $\geq 98 \%$ ). The cyanidin-3-O-glucoside chloride was diluted in distilled water. The chlorogenic acid and the chicoric acid were diluted in methanol. To quantify the amounts of anthocyanins and phenolic compounds, we made the standard curve of cyanidin-3-Oglucoside and chicoric acid. To construct the calibration curves, appropriate $10 \mathrm{mg} / \mathrm{mL}$ of cyanidin-3-O-glucoside chloride and chicoric acid were diluted with water and methanol, respectively. For cyanidin-3-O-glucoside chloride, four concentration levels $(0.1,0.15,0.2$ and $0.25 \mathrm{mg} / \mathrm{mL})$ were analyzed. For chicoric acid, five concentration levels $(0.05,0.1$, $0.15,0.2$ and $0.25 \mathrm{mg} / \mathrm{mL}$ ) were analyzed. The calibration curve showed linearly, with correlation coefficients 0.9979 and 0.9863 for cyanidin-3-O-glucoside chloride and chicoric acid, respectively. For quantification, peak areas were correlated with concentrations in accordance with the calibration curves. For Cy3G, Cy3MG, and Cy3MG-Me, cyanidin-3-Oglucoside chloride was used for calibration. For CTA, chlorogenic acid, CMA, chicoric acid, diCQA, chicoric acid equivalent was used. 
The amounts of compounds were expressed $\mu \mathrm{g}$ Cy3G equivalent (for anthocyain) or $\mathrm{mg}$ chicoric acid equivalent (for phenolic acids or flavonol derivative) per gram of plant material fresh weight.

The HPLC analysis was conducted three times using samples obtained from three independent experiments.

The LC-MS analyses were performed using the LCMS-8040 mass spectrometer with the Nexera X2 UHPLC system and the SPD-M30A diode array detector (Shimadzu Co., Kyoto, Japan). The LC conditions were the same as those used for the HPLC analysis, whereas the MS conditions were as follows: ionization mode: positive (for anthocyanins) and negative (for phenolics) electrospray ionization; capillary voltage: $4.5 \mathrm{kV}$; drying gas: $5 \mathrm{~L} / \mathrm{min}$; nebulizer gas: $2 \mathrm{~L} / \mathrm{min}$; desolvation line temperature: $250{ }^{\circ} \mathrm{C}$; heat block temperature: $450{ }^{\circ} \mathrm{C}$; and detection mode: selected ion monitoring (SIM). The $\mathrm{m} / \mathrm{z}$ of the detected ions were 449 (Cy3G), 535 (Cy3MG), 549 (Cy3MG-Me), 311 (CTA), 353 (chlorogenic acid), 295 (CMA), 473 (chicoric acids), 515 (diCQA), and 549 (unidentified compound). The LC-MS analysis was conducted three times using samples obtained from the independent experiments.

\subsection{Gene Expression Analysis of Phenylpropanoid Derivative Synthesis Genes in PDJ-Treated Lettuce}

We analyzed the expression-level changes to the phenylpropanoid synthesis genes in PDJ-treated lettuce by conducting a qPCR assay. The first and second leaves of five lettuce plants treated with or without $200 \mu \mathrm{M}$ PDJ were harvested at 0,24 and $48 \mathrm{~h}$ after the treatments. The collected leaves were stored in RNAlater solution (Thermo Fisher Scientific, Waltham, MA, USA) at $-20^{\circ} \mathrm{C}$ until used. Total RNA was extracted from the harvested leaves using the RNAprep Pure Plant Plus Kit with RNase-Free DNase I (TIANGEN Biotech Co. Ltd., Beijing, China). Specifically, leaves in RNAlater solution were transferred to $1.5 \mathrm{~mL}$ microtubes, which were weighed before the leaves were ground using a pestle homogenizer. The RNA was extracted according to the manufacturer's instructions. The total RNA quantity was determined using the NanoDrop 2000 spectrophotometer (Thermo Fisher Scientific, Waltham, MA, USA).

The extracted RNA served as the template for a reverse transcription using the Superscript IV VILO Master Mix kit (Thermo Fisher Scientific, Waltham, MA, USA). The total RNA $(1 \mu \mathrm{g})$ was mixed with the DNase solution comprising $1 \mu \mathrm{L} 10 \times$ ezDNase Buffer, $1 \mu \mathrm{L}$ ezDNase enzyme, and nuclease-free water (up to $10 \mu \mathrm{L}$ ) to digest genomic DNA at $37^{\circ} \mathrm{C}$ for $2 \mathrm{~min}$. The mixture was then placed on ice. After adding $4 \mu \mathrm{L}$ SuperScript IV VILO Master mix and $6 \mu \mathrm{L}$ nuclease-free water, the solution was incubated at $25^{\circ} \mathrm{C}$ for $10 \mathrm{~min}$ and then at $50{ }^{\circ} \mathrm{C}$ for $10 \mathrm{~min}$. To inactivate the enzyme, the mixture was incubated at $85{ }^{\circ} \mathrm{C}$ for $5 \mathrm{~min}$. The synthesized cDNA quantity was measured, after which the cDNA was stored at $-20^{\circ} \mathrm{C}$ until used.

The qPCR assay was performed using the 7500 Fast Real-Time System (Thermo Fisher Scientific, Waltham, MA, USA). We analyzed the expression of genes encoding chalcone synthase $(C H S)$, phenylalanine ammonia-lyase $(P A L)$, flavanone 3-hydroxylase $(F 3 H)$, anthocyanin synthase (ANS), UDP-glucose: flavonoid 3-O-glucosyltransferase (UFGT), dihydroflavonol 4-reductase (DFR), and actin (ACT). We designed gene-specific primers based on the information provided in a published article (Kitazaki et al. 2018) (Table S1). The primers were purchased from Integrated DNA Technologies Inc. (USA).

The qPCR was completed using the KOD SYBR qPCR kit (TOYOBO Co. Ltd., Osaka, Japan). The synthesized cDNA (500 ng in $5.6 \mu \mathrm{L}$ ) was mixed with $10 \mu \mathrm{L}$ KOD SYBR qPCR Mix, $4 \mu \mathrm{L}$ primer solution (forward and reverse primers, $0.2 \mu \mathrm{M}$ each), and $0.4 \mu \mathrm{L} 50 \times$ ROX reference dye. The PCR conditions were as follows: $50{ }^{\circ} \mathrm{C}$ for $2 \mathrm{~min}$ and $95^{\circ} \mathrm{C}$ for $10 \mathrm{~min} ; 45$ cycles of $95^{\circ} \mathrm{C}$ for $15 \mathrm{~s}$ and $60{ }^{\circ} \mathrm{C}$ for $60 \mathrm{~s}$. Expression data were obtained from three independent experiments. The expression levels of all analyzed genes were normalized against the $A C T$ expression level. The expression data were analyzed using the comparative $\mathrm{Ct}(\Delta \Delta \mathrm{Ct})$ method of the 7500 Fast Real-Time System software (version 2.0.5) 
(Thermo Fisher Scientific, Waltham, MA, USA). The qPCR assay was conducted three times using RNA samples obtained from three independent experiments.

\subsection{Statistical Analysis}

All data were analyzed using Microsoft Excel. Significant differences were estimated based on an ANOVA test $(p<0.05$ or 0.01$)$.

\section{Conclusions}

We identified the lettuce compounds affected by PDJ treatments. Additionally, we revealed that the expression of some lettuce genes related to the synthesis of anthocyanins and phenolics is upregulated by exogenous PDJ. We determined that PDJ treatments enhance the expression of genes encoding enzymes involved in phenylpropanoid synthesis pathways, thereby promoting the production of caffeic acid derivatives and anthocyanin derivatives in lettuce.

Supplementary Materials: The following are available online at https:/ /www.mdpi.com/article/ 10.3390/plants10091920/s1, Figure S1: Red leaf lettuce seedling treated without or with prohydrojasmon (PDJ), Figure S2: Mass spectrometry chromatograms (Selected Ion Monitoring: SIM) of the extracts from lettuce leaves not treated with PDJ, Figure S3. Mass spectrometry chromatograms (SIM) of the extracts from lettuce leaves treated with $100 \mu \mathrm{M}$ PDJ, Figure S4: Mass spectrometry chromatograms (SIM) of the extracts from lettuce leaves after $200 \mu \mathrm{M}$ PDJ treatments, Figure S5: Mass spectrometry spectra (Scan) of the extracts from lettuce leaves with $200 \mu \mathrm{M}$ PDJ treatments, Figure S6: UV-Vis spectra of the peaks found in the extracts from lettuce leaves with $200 \mu \mathrm{M}$ PDJ treatments, Figure S7: Chromatograms of the metabolites absorbing at $520 \mathrm{~nm}$ from lettuce plants treated with or without PDJ, Figure S8: Chromatograms of the metabolites absorbing at $325 \mathrm{~nm}$ from lettuce leaves with or without PDJ treatments, Table S1: Sequences of gene-specific qPCR primers.

Author Contributions: S.T., Y.N., T.S. and M.A. performed the experiments. H.R.A., T.S., M.A. helped analyze the data. M.K., H.F. and H.I. provided helpful discussions. S.T., Y.N., T.S., M.A. and H.I. prepared the manuscript. S.T. and H.I. designed the project. All authors have read and agreed to the published version of the manuscript.

Funding: This research was supported by funds from the Zeon Corporation, Tokyo, Japan (IndustryUniversity Collaboration between University of Tsukuba and Zeon Corporation, No. CDA29177). The funders had no role in the design of the study; in the collection, analysis, or interpretation of data; in the writing of the manuscript; or in the decision to publish the results.

Institutional Review Board Statement: Not applicable.

Informed Consent Statement: Not applicable.

Data Availability Statement: All our data, tables and figures in this manuscript are original. We have added our data availability statement. The data presented in this study are available in the article and its supplementary material.

Acknowledgments: We thank Selma Ettetib for her technical assistance with culturing red leaf lettuce plants and with measuring phenolic compound contents. We also thank Nobuyoshi Nakajima for his technical help with lyophilizing samples. We thank Yusaku Miyamae for preparing the graphical abstract. We thank Kazunori Sasaki for his technical help with using HPLC system. We acknowledge the NIES staff members who helped maintain the plant growth chamber.

Conflicts of Interest: The authors declare no conflict of interest.

\section{References}

1. Cartea, M.E.; Francisco, M.; Soengas, P.; Velasco, P. Phenolic Compounds in Brassica Vegetables. Molecules 2011, 16, 251-280. [CrossRef] [PubMed]

2. Arts, I.C.; Hollman, P.C.H. Polyphenols and disease risk in epidemiologic studies. Am. J. Clin. Nutr. 2005, 81, 317S-325S. [CrossRef] [PubMed]

3. Jahangir, M.; Kim, H.K.; Choi, Y.H.; Verpoorte, R. Health-Affecting Compounds in Brassicaceae. Compr. Rev. Food Sci. Food Saf. 2009, 8, 31-43. [CrossRef] 
4. Liu, R.H. Health benefits of fruit and vegetables are from additive and synergistic combinations of phytochemicals. Am. J. Clin. Nutr. 2003, 78, 517S-520S. [CrossRef]

5. Fraga, C.G.; Galleano, M.; Verstraeten, S.V.; Oteiza, P.I. Basic biochemical mechanisms behind the health benefits of polyphenols. Mol. Asp. Med. 2010, 31, 435-445. [CrossRef]

6. Dupont, M.S.; Mondin, Z.; Williamson, G.; Price, K.R. Effect of Variety, Processing, and Storage on the Flavonoid Glycoside Content and Composition of Lettuce and Endive. J. Agric. Food Chem. 2000, 48, 3957-3964. [CrossRef] [PubMed]

7. Nicolle, C.; Cardinault, N.; Gueux, E.; Jaffrelo, L.; Rock, E.; Mazur, A.; Amouroux, P.; Remesy, C. Health effect of vegetable-based diet: Lettuce consumption improves cholesterol metabolism and antioxidant status in the rat. Clin. Nutr. 2004, 23, 605-614. [CrossRef]

8. Llorach, R.; Martinez-Sanchez, A.; Tomas-Barberan, F.A.; Gil, M.I.; Ferreres, F. Characterisation of polyphenols and antioxidant properties of five lettuce varieties and escarole. Food Chem. 2008, 108, 1028-1038. [CrossRef]

9. Li, Z.; Zhao, X.; Sandhu, A.K.; Gu, L.W. Effects of Exogenous Abscisic Acid on Yield, Antioxidant Capacities, and Phytochemical Contents of Greenhouse Grown Lettuces. J. Agric. Food Chem. 2010, 58, 6503-6509. [CrossRef]

10. Becker, C.; Klaering, H.-P.; Kroh, L.W.; Krumbein, A. Cool-cultivated red leaf lettuce accumulates cyanidin-3-O-(6" $-O-$-malonyl)glucoside and caffeoylmalic acid. Food Chem. 2014, 146, 404-411. [CrossRef] [PubMed]

11. Kitazaki, K.; Fukushima, A.; Nakabayashi, R.; Okazaki, Y.; Kobayashi, M.; Mori, T.; Nishizawa, T.; Reyes-Chin-Wo, S.; Michelmore, R.W.; Saito, K.; et al. Metabolic Reprogramming in Leaf Lettuce Grown Under Different Light Quality and Intensity Conditions Using Narrow-Band LEDs. Sci. Rep. 2018, 8, 7914. [CrossRef] [PubMed]

12. Lee, M.-J.; Son, J.E.; Oh, M.-M. Growth and phenolic compounds of Lactuca sativa L. grown in a closed-type plant production system with UV-A, -B, or -C lamp. J. Sci. Food Agric. 2014, 94, 197-204. [CrossRef]

13. Sparvoli, F.; Martin, C.; Scienza, A.; Gavazzi, G.; Tonelli, C. Cloning and molecular analysis of structural genes involved in flavonoid and stilbene biosynthesis in grape (Vitis vinifera L.). Plant Mol. Biol. 1994, 24, 743-755. [CrossRef] [PubMed]

14. Su, N.; Lu, Y.; Wu, Q.; Liu, Y.; Xia, Y.; Xia, K.; Cui, J. UV-B-induced anthocyanin accumulation in hypocotyls of radish sprouts continues in the dark after irradiation. J. Sci. Food Agric. 2015, 96, 886-892. [CrossRef]

15. Zhou, W.W.; Liang, X.; Zhang, Y.X.; Dai, P.B.; Liang, B.; Li, J.L.; Sun, C.L.; Lin, X.Y. Role of sucrose in modulating the lownitrogen-induced accumulation of phenolic compounds in lettuce (Lactuca sativa L.). J. Sci. Food Agric. 2020, 100, 5412-5421. [CrossRef]

16. Li, T.; Jia, K.-P.; Lian, H.-L.; Yang, X.; Li, L.; Yang, H.-Q. Jasmonic acid enhancement of anthocyanin accumulation is dependent on phytochrome A signaling pathway under far-red light in Arabidopsis. Biochem. Biophys. Res. Commun. 2014, 454, 78-83. [CrossRef]

17. Creelman, R.A.; Mullet, J.E. Jasmonic acid distribution and action in plants: Regulation during development and response to biotic and abiotic stress. Proc. Natl. Acad. Sci. USA 1995, 92, 4114-4119. [CrossRef]

18. Rohwer, C.L.; Erwin, J.E. Horticultural applications of jasmonates: A review. J. Hortic. Sci. Biotech. 2008, 83, 283-304. [CrossRef]

19. Mandour, N.S.; Kainoh, Y.; Ozawa, R.; Uefune, M.; Takabayashi, J. Effects of prohydrojasmon-treated corn plants on attractiveness to parasitoids and the performance of their hosts. J. Appl. Entomol. 2013, 137, 104-112. [CrossRef]

20. Cetinbas, M.; Butar, S.; Sesli, Y.; Sekmen, S.; Yaman, B. The Effects of Pre-Harvest Prohydrojasmon Application on Yield and Fruit Quality of 'Starking Delicious' Apples in Different Locations. Fresen. Environ. Bull. 2018, 27, 7438-7445.

21. Azis, H.R.; Takahashi, S.; Koshiyama, M.; Fujisawa, H.; Isoda, H. Effect of Prohydrojasmon on the Growth of Eggplant and Komatsuna. Plants 2020, 9, 1368. [CrossRef]

22. Sato, K.; Ikoma, Y. Improvement in Handpicking Efficiency of Satsuma Mandarin Fruit with Combination Treatments of Gibberellin, Prohydrojasmon and Ethephon. Hortic. J. 2017, 86, 283-290. [CrossRef]

23. Pu, C.-H.; Lin, S.-K.; Chuang, W.-C.; Shyu, T.-H. Modified QuEChERS method for 24 plant growth regulators in grapes using LC-MS/MS. J. Food Drug Anal. 2018, 26, 637-648. [CrossRef]

24. Sudheeran, P.K.; Love, C.; Feygenberg, O.; Maurer, D.; Ovadia, R.; Oren-Shamir, M.; Alkan, N. Induction of red skin and improvement of fruit quality in 'Kent', 'Shelly' and 'Maya' mangoes by preharvest spraying of prohydrojasmon at the orchard. Postharvest Biol. Technol. 2019, 149, 18-26. [CrossRef]

25. Kumar, S.P.; Maurer, D.; Feygenberg, O.; Love, C.; Alkan, N. Improving the Red Color and Fruit Quality of 'Kent' Mango Fruit by Pruning and Preharvest Spraying of Prohydrojasmon or Abscisic Acid. Agronomy 2020, 10, 944. [CrossRef]

26. Wang, X.Q.; Cao, X.Y.; Shang, Y.; Bu, H.D.; Wang, T.Y.; Lyu, D.G.; Du, G.D. Preharvest application of prohydrojasmon affects color development, phenolic metabolism, and pigment-related gene expression in red pear (Pyrus ussuriensis). J. Sci. Food Agric. 2020, 100, 4766-4775. [CrossRef]

27. Azis, H.R.; Etteieb, S.; Takahashi, S.; Koshiyama, M.; Fujisawa, H.; Isoda, H. Effect of prohydrojasmon on total phenolic content, anthocyanin accumulation and antioxidant activity in komatsuna and lettuce. Biosci. Biotechnol. Biochem. 2020, 84, 178-186. [CrossRef]

28. Schütz, K.; Persike, M.; Carle, R.; Schieber, A. Characterization and quantification of anthocyanins in selected artichoke (Cynara scolymus L.) cultivars by HPLC-DAD-ESI-MSn. Anal. Bioanal. Chem. 2006, 384, 1511-1517. [CrossRef]

29. Mulabagal, V.; Ngouajio, M.; Nair, A.; Zhang, Y.; Gottumukkala, A.L.; Nair, M.G. In vitro evaluation of red and green lettuce (Lactuca sativa) for functional food properties. Food Chem. 2010, 118, 300-306. [CrossRef] 
30. Carazzone, C.; Mascherpa, D.; Gazzani, G.; Papetti, A. Identification of phenolic constituents in red chicory salads (Cichorium intybus) by high-performance liquid chromatography with diode array detection and electrospray ionisation tandem mass spectrometry. Food Chem. 2013, 138, 1062-1071. [CrossRef]

31. Brito, A.; Areche, C.; Sepulveda, B.; Kennelly, E.J.; Simirgiotis, M.J. Anthocyanin characterization, total phenolic quantification and antioxidant features of some Chilean edible berry extracts. Molecules 2014, 19, 10936-10955. [CrossRef] [PubMed]

32. Budryn, G.; Nebesny, E.; Podsędek, A.; Żyżelewicz, D.; Materska, M.; Jankowski, S.; Janda, B. Effect of different extraction methods on the recovery of chlorogenic acids, caffeine and Maillard reaction products in coffee beans. Eur. Food Res. Technol. 2009, 228, 913-922. [CrossRef]

33. Liang, Y.-S.; Choi, Y.H.; Kim, H.K.; Linthorst, H.J.M.; Verpoorte, R. Metabolomic analysis of methyl jasmonate treated Brassica rapa leaves by 2-dimensional NMR spectroscopy. Phytochemistry 2006, 67, 2503-2511. [CrossRef]

34. Materska, M.; Olszówka, K.; Chilczuk, B.; Stochmal, A.; Pecio, Ł.; Pacholczyk-Sienicka, B.; Piacente, S.; Pizza, C.; Masullo, M. Polyphenolic profiles in lettuce (Lactuca sativa L.) after $\mathrm{CaCl}_{2}$ treatment and cold storage. Eur. Food Res. Technol. 2018, 245, 733-744. [CrossRef]

35. Sobolev, V.S.; Horn, B.W.; Potter, T.L.; Deyrup, S.; Gloer, J.B. Production of Stilbenoids and Phenolic Acids by the Peanut Plant at Early Stages of Growth. J. Agric. Food Chem. 2006, 54, 3505-3511. [CrossRef]

36. Tong, J.; Ma, B.; Ge, L.; Mo, Q.; Zhou, G.; He, J.; Wang, Y. Dicaffeoylquinic Acid-Enriched Fraction of Cichorium glandulosum Seeds Attenuates Experimental Type 1 Diabetes via Multipathway Protection. J. Agric. Food Chem. 2015, 63, 10791-10802. [CrossRef]

37. Zhao, H.; Chen, W.; Lu, J.; Zhao, M. Phenolic profiles and antioxidant activities of commercial beers. Food Chem. 2010, 119, 1150-1158. [CrossRef]

38. Ribas-Agusti, A.; Gratacos-Cubarsi, M.; Sarraga, C.; Garcia-Regueiro, J.A.; Castellari, M. Analysis of Eleven Phenolic Compounds Including Novel p-Coumaroyl Derivatives in Lettuce (Lactuca sativa L.) by Ultra-high-performance Liquid Chromatography with Photodiode Array and Mass Spectrometry Detection. Phytochem. Anal. 2011, 22, 555-563. [CrossRef]

39. Damerum, A.; Selmes, S.L.; Biggi, G.F.; Clarkson, G.J.; Rothwell, S.D.; Truco, M.J.; Michelmore, R.W.; Hancock, R.; Shellcock, C.; Chapman, M.; et al. Elucidating the genetic basis of antioxidant status in lettuce (Lactuca sativa). Hortic. Res. $2015,2,15055$. [CrossRef]

40. Gurdon, C.; Poulev, A.; Armas, I.; Satorov, S.; Tsai, M.; Raskin, I. Genetic and Phytochemical Characterization of Lettuce Flavonoid Biosynthesis Mutants. Sci. Rep. 2019, 9, 3305. [CrossRef]

41. Brugliera, F.; Tao, G.Q.; Tems, U.; Kalc, G.; Mouradova, E.; Price, K.; Stevenson, K.; Nakamura, N.; Stacey, I.; Katsumoto, Y.; et al. Violet/blue chrysanthemums-metabolic engineering of the anthocyanin biosynthetic pathway results in novel petal colors. Plant Cell Physiol. 2013, 54, 1696-1710. [CrossRef]

42. Taguchi, G.; Ubukata, T.; Nozue, H.; Kobayashi, Y.; Takahi, M.; Yamamoto, H.; Hayashida, N. Malonylation is a key reaction in the metabolism of xenobiotic phenolic glucosides in Arabidopsis and tobacco. Plant J. 2010, 63, 1031-1041. [CrossRef]

43. Neill, S.O.; Gould, K.S. Anthocyanins in leaves: Light attenuators or antioxidants? Funct. Plant Biol. 2003, 30, 865-873. [CrossRef]

44. Becker, C.; Klaering, H.-P.; Schreiner, M.; Kroh, L.W.; Krumbein, A. Unlike Quercetin Glycosides, Cyanidin Glycoside in Red Leaf Lettuce Responds More Sensitively to Increasing Low Radiation Intensity before than after Head Formation Has Started. J. Agric. Food Chem. 2014, 62, 6911-6917. [CrossRef] [PubMed]

45. Clifford, M.N.; Jaganath, I.B.; Ludwig, I.A.; Crozier, A. Chlorogenic acids and the acyl-quinic acids: Discovery, biosynthesis, bioavailability and bioactivity. Nat. Prod. Rep. 2017, 34, 1391-1421. [CrossRef] [PubMed]

46. Kim, H.-J.; Chen, F.; Wang, X.; Choi, J.-H. Effect of Methyl Jasmonate on Phenolics, Isothiocyanate, and Metabolic Enzymes in Radish Sprout (Raphanus sativus L.). J. Agric. Food Chem. 2006, 54, 7263-7269. [CrossRef] [PubMed]

47. Flores, G.; del Castillo, M.L.R. Influence of preharvest and postharvest methyl jasmonate treatments on flavonoid content and metabolomic enzymes in red raspberry. Postharvest Biol. Technol. 2014, 97, 77-82. [CrossRef]

48. Shan, X.Y.; Zhang, Y.S.; Peng, W.; Wang, Z.L.; Xie, D.X. Molecular mechanism for jasmonate-induction of anthocyanin accumulation in Arabidopsis. J. Exp. Bot. 2009, 60, 3849-3860. [CrossRef] [PubMed]

49. Fernandez-Milmanda, G.L.; Crocco, C.D.; Reichelt, M.; Mazza, C.A.; Kollner, T.G.; Zhang, T.; Cargnel, M.D.; Lichy, M.Z.; Fiorucci, A.S.; Fankhauser, C.; et al. A light-dependent molecular link between competition cues and defence responses in plants. Nat. Plants 2020, 6, 223-230. [CrossRef] 